\title{
PERCEIVED SOCIAL SUPPORT
} AS PREDICTOR OF UNIVERSITY

\section{ADJUSTMENT AND ACADEMIC ACHIEVEMENT AMONGST FIRST YEAR UNDERGRADUATES IN A MALAYSIAN PUBLIC UNIVERSITY}

\author{
${ }^{1}$ Maria Chong Abdullah, ${ }^{2}$ Luo Lan Kong \\ \& ${ }^{3}$ Abd Rahim Talib

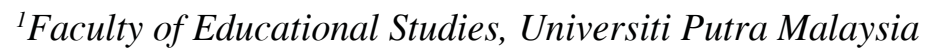 \\ ${ }^{2}$ Smart Reader International College \\ ${ }^{3}$ Specialist Teachers' Training Campus, Teacher Training Institute
}

${ }^{1}$ Corresponding author: mariachong2002@yahoo.com

\begin{abstract}
Purpose - This study was conducted to examine relationships between perceived social support, university adjustment and academic achievement of first semester students enrolled in various undergraduate programs in a Malaysian public university.
\end{abstract}

Methodology - This study employed a quantitative approach with a descriptive correlation design to address the research objectives. The adapted version of the "Interpersonal Support Evaluation List" (1985) and the "Student Adaptation to College Questionnaire" (1999) were used to assess students' perceived social support and university adjustment respectively. A total of 250 first year undergraduates were selected as respondents using cluster random sampling technique.

Findings - Findings revealed a significant and positive relationship between students' perceived social support and their overall university adjustment as well as all the four adjustment dimensions namely academic adjustment, social adjustment, personal-emotional adjustment, attachment to university, and academic achievement. 
Results also indicated that students' overall university adjustment and academic achievement were significant and positively predicted by social support.

Significance - This study provides important evidence for undergraduates, lecturers, university administrators, and the community at large regarding the important role of social support in university adjustment and academic performance. It is suggested that a university should provide support services to assist new undergraduates to overcome their adjustment problems.

Keywords: Academic achievement, university adjustment, social support, undergraduates

\section{INTRODUCTION}

The transition from high school to a tertiary institution of learning can be considered as a major life changing experience for many youths (Salami, 2011). This event is supposed to be a very appealing and beneficial experience for them as attending a tertiary institution of learning offers students great opportunities for psychosocial development (Friedlander, Reid, Shupak, \& Cribbie, 2007; Tao, Dong, Pratt, Hunsberger, \& Pancer, 2000). However, previous studies have reported that the transition to university can be a source of strain and an acute stressor (Friedlander et al., 2007; Perry, Hladkyj, Pekrun, \& Pelletier, 2001). According to Parker, Summerfeldt, Hogan, and Majeski (2004), new undergraduates are confronted with various new personal and interpersonal challenges. For example, they need to build new relationships, to modify existing relationship with parents and family members, and to develop new learning habits in a new academic environment. These new undergraduates are more likely to drop out from university if they fail to meet these challenges (Gerdes \& Mallinckrodt, 1994). According to Tinto (1993) and Martin, Swartz, and Madson (1999), one reason new undergraduates dropped out of college was due to adjustment difficulties. Studies have also demonstrated that adjustment among first year undergraduates has a strong impact on their academic achievement (Martin et al., 1999; Sennett, Finchilescu, Gibson, \& Strauss, 2003). 


\section{PROBLEM STATEMENT}

According to a study conducted by Ahmad, Noran Fauziah, Azemi and Mohd. Zailani (2002) in a local public university, the adjustment problems faced by new undergraduates include academic problems, health problems, financial crises as well as social and personal problems. For example, some of the academic problems faced by students were: unable to register for courses, difficult to understand textbooks written in English, and unable to attend lecture as early as eight in the morning. Financial problems included receiving funds late from the provider or the received amount of fund was not enough to cover the expenses during the course of study. On top of that, students also found difficulty in taking care of their health.

Based on the senario mentioned above, the adjustment process undergone by new unergraduates should be given appropriate attention as serious adjustment problems experienced by these students could lead to the failure in completing their studies. The importance of adjustment among new undergraduates has encouraged a great deal of studies to explore the factors that are related to it. Social support is among the psychological factors that has been identified as an important predictor of college adjustment (Cauce, Mason, Gonzales, Hiraga, \& Liu, 1994; Eldeleklioğlu, 2006; Napoli \& Wortmen 1998) and academic achievement (DeBerard, Spielmans, \& Julka, 2004; Spitzer, 2000) among new university students. In a study conducted by Mattanah, Brooks, Brand, Quimby, and Ayers (2012), it was reported that students who seek support from faculty and peers were more likely to succeed academically.

\section{Theoretical Perspective}

In this study, social support refers to the resources or assistance available in campus as perceived by new undergraduates. The concept of social support employed in this study was proposed by Cohen, Mermelstein, Kamarck, and Hoberman (1985) who referred to social support as resources provided to an individual by others. While other psychologists focused on the role of one's social network such as friends, relatives and acquaintances in ensuring his or her health and well being. Cohen et al. (1985) in their own theoretical 
work argued that one's personal relationships functioned as stress buffers only when the type of support resources that were provided by one's relationship matched the coping requirements elicited by the stressor(s). For example, a monetary loan may benefit a student who has a problem in settling the tuition fee, but the same resource would be ineffective as a response to a student who is in need of advice or cognitive guidance. Hence, Cohen et al. (1985) and Cohen (1992) proposed a Stressor-Resource Matching model which posited perceived support as the source of stress buffering. According to this model, stress buffering occurs only when there is a match between the needs elicited by the stressful event and the functions of support that are perceived to be present (Cohen \& McKay, 1984). Cohen et al. (1985) and Delistamati, Samakouri, Davis, Vorvolakos, Xenitidis \& Livaditis (2006) have identified four types of perceived support that can be utilized to handle stress in one's life. These supports are: (1) Tangible support (refers to opportunities to get the material or equipment support); (2) Appraisal support (refers to opportunities to get someone to talk about the problem or someone to provide advice, guidance and information needed); (3) Self-esteem support (refers to the self-recognition through social comparison); and (4) Belonging support (refers to the the opportunities to build friendships, or get a friend to do an activity together).

\section{Social Support and University Adjustment}

Social support among adults has been studied extensively over the past few decades. These studies indicated that social support contributes to the physical and psychological well-being of adults, thus reducing the negative effects of life stress experienced by them (Cauce et al., 1994; Cohen, 1992). A study conducted by Sharifah Azizah and Rosna (2011) reported that teacher and parental support were significantly related to adolescents' cognitive engagement through their academic efficacy. Other studies showed that support from parents, friends, teachers, and significant others contributed to academic, social and emotional development of first year undergraduates (Friedlander et al., 2007; Tao et al., 2000).

Previous studies by Napoli and Wortman (1998), Schneider and Ward (2003), Lidy and Kahn, (2006), Crockett at al. (2007), Yusliza (2011), and Salami (2011) have revealed a positive relationship between social support and adjustment among university students. For example, Lidy and Kahn (2006) in a study involving 111 new 
students at a public university in the Midwest reported that social support had a direct effect on the dimensions of academic adjustment ( $\beta=.28, p=.01)$, social adjustment $(\beta=.39, p=.01)$, and institutions linkage $(\beta=.31, p=.01)$. The relationship between social support and adjustment were also reported in the study by Salami (2011) involving 250 first year college students. Findings in Salami's (2011) study showed that students who have sources of social support from friends and family members, such as guidance feedback, intimacy, positive social interactions and tangible assistance are likely to be able to handle effectively academic, social, and personal-emotional problems in their new college environment. Similar results were also reported by Yusliza (2011) in a study involving 185 international students enrolled in one of the Malaysian public universities. Using the Multidimensional Scale of Perceived Social Support (MSPSS) developed by Zimet, F. D., Dahlem, N. W., Zimet, S. G., \& Farley, G. K. (1988), Yusliza's study revealed that only one dimension of the MSPSS which is the support from friends and significant others was found to show significant relationship with psychological adjustment among the students. Overall, the aforementioned studies had shown that social support contribute to the adjustment of students in university.

\section{Social Support and Academic Achievement}

Besides university adjustment, social support was reported to be associated with students' academic achievement as well (Hackett, Betz, Casas, \& Rocha-Singh, 1992; Napoli \& Wortman, 1998; Spitzer, 2000; DeBerard et al., 2004; Md Aris Safree \& Mariam Adawiah, 2011; and Mattanah et al., 2012). For example, Md Aris Safree and Mariam Adawiah (2011) reported that the social support attained by 120 undergraduate students in a public university in Malaysia revealed a significant and positive relationship to their academic achievement, indicating that the higher the social support, the higher the academic achievement of the students. In summary, previous studies indicated that social support not only had an impact on students' adjustment, but also their academic performance.

\section{OBJECTIVES OF THE STUDY}

Given the many implications of the importance of social support in undergraduates' adjustment to university, this study has been 
warranted to examine the relationship between undergraduates' social support and adjustment to university and academic achievement in a local public university. In addition, since most of the studies on social support and university adjustment were conducted in universities abroad, the current study is important to share some light on the same issues based on the local scenario and culture. On top of that, the present study utilized different instruments for assessing social support as well as adjustment of the undergraduates as compared to those in the past. For example, social support among the subjects in the present study was assessed using the Interpersonal Social Evaluation List-College Version (ISEL) while the Multidimensional Scale of the Perceived Social Support (MSPSS) was used in studies conducted by Salami (2011) and Yusliza (2011) for the same purpose. The Social Support Behaviors Scale was used in another study by Md Aris Safree and Mariam Adawiah (2011). Generally, the current study was aimed at providing empirical evidence and important information to undergraduates, lecturers, university administrators, and the community at large pertaining to the important role of social support in university adjustment and academic performance among new undergraduates. Specifically, this research was intended to address the following objectives:

(1) To identify the level of social support amongst first year undergraduate students.

(2) To determine the relationship between social support and university adjustment and academic achievement among first year undergraduates.

(3) To determine the extent to which the variance of adjustment and academic achievement among new undergraduate students are explained by social support.

\section{METHODOLOGY}

The present study employed a quantitative approach with a descriptive correlation design. A total of 250 first year undergraduates with a mean age of $19.37(S D=1.19)$ participated in this study. They were selected (ranging from 20 to 25 students from each faculty) from six different faculties (Faculty of Engineering, Faculty Medicine and Health Sciences, Faculty of Environmental Studies, Faculty of Educational Studies, Faculty of Modern Language and 
Communication, and Faculty of Economics and Management) in one of the local public university using a cluster random sampling technique. The sample comprised $71(28.4 \%)$ males and $179(71.6 \%)$ females. In terms of ethnic groups, there were 192 (76.8\%) Malays, 43 Chinese (17.2\%), 8 Indians (3.2\%), and 7 others (2.8\%).

\section{Instrumentation}

Two instruments were administered to collect the research data. They were the adapted version of the Adaptation to College Questionnaire (SACQ) and the Interpersonal Social Evaluation ListCollege Version (ISEL). The first version of the SACQ contained 52 items and was developed by Baker and Siryk (1984). The SACQ used in the current study contained 67 items and was published in 1999 (Baker \& Siryk, 1999). The SACQ was made up of four sub scales that measured four different types of university adjustment dimensions, namely academic adjustment, social adjustment, personal-emotional adjustment, and institutional attachment. The SACQ consists of 67 self-rating responses using a 9-point scales ranging from "applies very closely to me" (9) on the left to "doesn't apply to me at all" (1) on the right. However, the scales for 34 of the items (the negatively keyed items such as "I am finding academic work at college difficult") were reversely scored (values run from 1 to 9). The SACQ yields full scales scores and four subscale scores for the four adjustment dimensions as mentioned above. The higher the scores obtained by the respondents the better self-assessed adjustment to college being reported by them, and vice versa. The reliability of the SACQ in the present study was found to be high ( $\alpha$ $=.91$ ). The same goes for the four subscales which ranges from .78 to .86 for the alpha values.

The Interpersonal Social Evaluation List-College Version (ISEL) used in this study was developed by Cohen et al. (1985). The ISEL was designed to assess students' perception of the availability of social support in campus. The ISEL comprises 48 items which assess 4 social support dimensions, such as tangible, appraisal, selfesteem, and belonging support. The ISEL requires respondents to rate the availability of social support perceived by them based on a four point Likert type scale such as 1 for 'disagree', 2 for 'less agree', 3 for 'agree', and 4 for 'strongly agree'. The ISEL used in 
this study was found to be reliable $(\alpha=.90)$. The alpha values for the four subscales were found to range from .74 to .87. Students' academic achievement in this study was assessed based on their grade point average (GPA) obtained at the end of the first semester.

Both instruments (SACQ and ISEL) were translated into the Malay language before they were utilized for data collection purposes. Back-to back translations and content validity were conducted and confirmed for both instruments by language experts as well as psychologists.

\section{RESULTS}

To address the first objective of this study, students' level of social support was obtained from the ISEL. The raw scores were analyzed and categorized into three categories based on the Likert scores such as low (1 to 2 ), moderate (2.01 to 3 ), and high (3.01 to 4). The results in Table 1 shows that the mean score for social support was $2.78(S D=0.34)$. This result indicates that respondents have a moderate satisfaction level of perceived campus social support. The highest satisfaction level of social support reported by the respondents was appraisal support $(M=2.98, S D=.52)$, followed by belonging support $(M=2.89, S D=.43)$, tangible support $(M=$ $2.84, S D=.48)$, and self-esteem support $(M=2.40, S D=.46)$. This finding indicates that the satisfaction level of self-esteem support reported by respondents was the lowest compared with the three other types of social support.

Table 1

Distribution of the Mean Scores of Social Support among Respondents

\begin{tabular}{|c|c|c|c|c|c|}
\hline \multirow[b]{2}{*}{$\begin{array}{c}\text { Descriptive } \\
\text { Statistics }\end{array}$} & \multicolumn{5}{|c|}{ Variables } \\
\hline & $\begin{array}{c}\text { Overall } \\
\text { Social } \\
\text { Support }\end{array}$ & $\begin{array}{l}\text { Tangible } \\
\text { Support }\end{array}$ & $\begin{array}{c}\text { Appraisal } \\
\text { Support }\end{array}$ & $\begin{array}{c}\text { Self- } \\
\text { Esteem } \\
\text { Support }\end{array}$ & $\begin{array}{c}\text { Belonging } \\
\text { Support }\end{array}$ \\
\hline Mean & 2.78 & 2.84 & 2.98 & 2.40 & 2.89 \\
\hline Standard Deviation & 0.34 & 0.48 & 0.52 & 0.46 & 0.43 \\
\hline
\end{tabular}

Note $\mathrm{N}=250$ 
A Pearson product-moment correlation was further conducted to address the second objective of this study, and that is to determine the relationship between social support and university adjustment and academic achievement among first year undergraduates. Results in Table 2 show that there were significant and positive relationships between undergraduates' overall social support scores and their overall adjustment scores $(r=.51, p<.01)$. On top of that, social support was found to exhibit significant and positive relationship with all the adjustment dimensions, such as academic adjustment $(r=.40, p<.01)$, social adjustment $(r=.19, p<.01)$, personalemotional adjustment $(r=.14, p<.01)$, and university attachment $(r=.18, p<.05)$. Results in Table 2 also denotes that there was a significant and positive relationship between undergraduates' overall social support scores and their academic achievement $(r=.33, p<.01)$.

Table 2

Pearson Correlation Coeficient between Social Support and University Adjustment and Academic Achievement

\begin{tabular}{ccccccc}
\hline Variables & $\begin{array}{c}\text { Overall } \\
\text { Academic } \\
\text { Adjustment }\end{array}$ & $\begin{array}{c}\text { Academic } \\
\text { Adjustment }\end{array}$ & $\begin{array}{c}\text { Social } \\
\text { Adjustment }\end{array}$ & $\begin{array}{c}\text { Emotional- } \\
\text { personal } \\
\text { Adjustment }\end{array}$ & $\begin{array}{c}\text { University } \\
\text { Attachment }\end{array}$ & $\begin{array}{c}\text { Academic } \\
\text { Achievement }\end{array}$ \\
\hline Social Support & $.51 * *$ & $.40^{* *}$ & $.19 * *$ & $.14 *$ & $.18^{* *}$ & $.33 * *$ \\
\hline
\end{tabular}

Note $\mathrm{N}=250 ; * *$ : Correlation is significant at .01 level (2-tailed); *: Correlation is significant at .05 level (2-tailed).

To address the third objective in this study, two linear regression analyses were conducted to determine the amount of variance in university adjustment and academic achievement explained by undergraduates' social support. Results in Table 3 shows that social support was a significant predictor of undergraduates' overall adjustment to university and academic achievement. Social support accounted for $26 \%\left(R^{2}=.26\right)$ of the variance in students' adjustment to university, and $4 \%\left(R^{2}=.04\right)$ of the variance in their academic achievement. 
Table 3

Simple Linear Regression Analyses of Social Support as Predictor of University Adjustment and Academic Achievement

\begin{tabular}{|c|c|c|c|c|c|c|c|c|}
\hline \multirow[t]{2}{*}{ Variables } & \multicolumn{4}{|c|}{$\begin{array}{l}\text { University Adjustment (Model 1) } \\
F(1,248)=86.03, p=.000 ; R^{2}=.26\end{array}$} & \multicolumn{4}{|c|}{$\begin{array}{l}\text { Academic Achievement (Model 2) } \\
F(1,248)=9.27, p=.003 ; R^{2}=.04\end{array}$} \\
\hline & B & $\beta$ & $\mathrm{t}$ & $\mathrm{p}$ & $\mathrm{B}$ & $\beta$ & $\mathrm{t}$ & $\mathrm{p}$ \\
\hline Social Support & 2.70 & .51 & 9.28 & .000 & 2.57 & .19 & 3.04 & .003 \\
\hline
\end{tabular}

Note: $\mathrm{N}=250$

\section{DISCUSSION}

The significant relationship found between social support and university adjustment have provided significant information pertaining to the importance of the availability of social support perceived by students in relation to their adjustment to the university. Findings also revealed that social support among the undergraduates contributed not only to their overall university adjustment, but also to all the four adjustment dimensions (academic adjustment, social adjustment, emotional-personal adjustment, and university attachment). This finding concurred with the findings of previous researches which reported similar results (Salami, 2011; Friedlander et al., 2007; Halamandaris \& Power, 1999; Tao et al., 2000). This finding provides evidence that students who perceived that social support was available in campus were likely to be able to cope effectively with their academic, social, and personal-emotional problems. They were also predicted to show a higher degree of committment to educational-institutional goals and higher degree of attachment to the institutions they were attached to. In addition, the present study indicated a significant relationship between social suppport and academic achievement and this finding has further supported the importance of social support in undergraduates' academic performance.

Overall, the findings from this study implies that the more social support perceived by new undergraduates in the university environment, the better they are in adjusting themselves to campus life (in terms of physical and psychological well-being), and the 
higher the academic achievement (CGPA) obtained by them. These findings concurred with the findings of previous studies which demonstrated the positive impact of social support on university adjustment (Cauce et al., 1994; Crockett at al., 2007; Friedlander et al., 2007; Lidy \& Kahn, 2006; Napoli \& Wortman, 1998; Salami, 2011; Schneider \& Ward, 2003; Smith \& Renk, 2007; Tao et al., 2000; Yusliza (2011) as well as academic achievement (DeBerard et al., 2004; Hackett et al., 1992; Mattanah et al., 2012; Md Aris Safree \& Mariam Adawiah, 2011; Spitzer, 2000) among new undergraduates.

\section{CONCLUSION}

This study has provided evidence that social support is an important predictor in determining both the adjustment and academic achievement among new undergraduates. Hence, it is important for those who are involved in tertiary education such as lecturers, academic advisors, and university administrators to provide support services to assist new undergraduates who experience adjustment problems and to prepare them to proceed to the following semester with less problems. For example, Norzaini, Manisah, Abd Halim and Zalizan (2005), in their studies suggested that lecturers need to have frequent contact with students to stimulate their learning. As suggested by Tinto (1993), instructors are encouraged to establish informal interaction with students outside the classroom or lab, as rewarding interactions between students and the faculty staff outside the classroom may enhance intellectual development and therefore create greater intellectual integration among students within the academic system of the university. On the other hand, the absence of informal student-faculty interactions may lead to academic boredom and thus, lower the levels of academic performance which may in turn lead to dismissal (Tinto, 1993). Besides the teaching staff, the involvement of senior students as mentors or tutors to new undergraduates should be encouraged as senior students are found to significantly influence junior students' social adjustment and attachment to university (Hurtado, Carter, \& Spuler, 1996). According to Popejoy (1994), tutors or mentors and trained senior students are well accepted and liked by new students and are seen as the most effective people to help these groups of students. Findings from the current study have also supported the Stressor- 
Resource Mactching model proposed by Cohen et al. (1985) and Cohen (1992). Hence, it is also suggested that a 'needs analysis' of new undergraduates pertaining to campus adjustment be conducted before designing any intervention programs or support services in relation to social support. This is to ensure that the programs and support services intended are in line with the resources required by them.

The results of the current study should be viewed in light of its limitations. First, this study is a cross sectional study where the data were collected from the respondents simultaneously for a period of time. Thus, the undergraduates' development of social support through the course were not assessed based on their studying period. With that in mind, future studies are suggested using the longitudinal method to examine the development/progress of undergraduates' social support according to their learning period in the university. Future research can also be conducted to investigate the impact of other factors on university adjustment and academic achievement such as demographic factors (for example: gender, year and program of study) and other psychological factors which may include students' emotional regulation ability, coping ability, self-esteem, academic self-efficacy and self regulation, and time perspective.

\section{REFERENCES}

Ahmad Khamis, Noran Fauziah Yaakub, Azemi Shaari, Mohd. Zailani Mohd. Yusoff. (2002). Adjustment to college life and academic performance among Universiti Utara Malaysia students. (Unpublished manuscript). Universiti Utara Malaysia, Kedah, Malaysia.

Baker, R. W., \& Siryk, B. (1984). Measuring adjustment to college. Journal of Counselling Psychology, 31(2), 179-189.

Baker, R. W., \& Siryk, B. (1999). SACQ: Student adaptation to college questionnaire manual (2nd ed.). Los Angeles: Western Psychological Services.

Cauce, A. M., Mason, C., Gonzales, N., Hiraga, Y., \& Liu, G. (1994). Social support during adolscence: methodological and theoretical considerations. In F. Nestmann \& K. Hurrelmann (Eds.), Social networks and social support in childhood and adolescence (pp. 89-108). Berlin: Walterde Gruyter. 
Cohen, S. (1992). Stress, social support, and disorder. In H. O. F., Veiel, \& U. Baumann (Eds.), The meaning and measurement of social support (pp. 109-124). New York: Hemisphere Press. Cohen, S., \& McKay, G. (1984). Social support, stress, and the buffering hypothesis: A theoretical analysis. In A. Baum, J. E. Singer, \& S. E. Taylor (Eds.), Handbook of psychology and health, Vol. 4 (pp. 253-267), Jillsdale, NJ: Erlbaum.

Cohen, S., Mermelstein, R., Kamarck, T., \& Hoberman, H. M. (1985).

Measuring the functional components of social support. In I.

G., Sarason \& B. R., Sarason, (Eds.), Social support: Theory, research, \& application (pp. 73-94). Dordrecht: Martinus Nijhoff. Crockett, L. J., McGinley, M., Iturbide, M. I., Raffaelli, M., Torres Stone, R. A., \& Carlo, G. (2007). Acculturative stress, social support and coping: Relations to psychological adjustment among Mexican American college students. Cultural Diversity and Ethnic Minority Psychology, 13(4), 347-355.

DeBerard, M. C., Spielmans, G. I., \& Julka, D. C. (2004). Predictors of academic achievement and retention among college freshmen: a longitudinal study. College Student Journal, 38(1), 66-80.

Delistamati, E., Samakouri, M. A., Davis, E. A., Vorvolakos, T., Xenitidis, K., \& Livaditis, M. (2006). Interpersonal Support Evaluation List (ISEL) - College Version: Validation and application in a Greek sample. International Journal of Social Psychiatry, 52(6), 552-560.

Eldeleklioğlu, J. (2006). The relationship between the peceived social support and the level of depression and anxiety in university students. Educational Science: Theory \& Practice, 6(3), 742-752.

Friedlander, L. J., Reid, G. J., Shupak, N., \& Cribbie, R. (2007). Social support, self-esteem and stress as predictors of adjustment to university among first - year undergraduates. Journal of College Student Development, 46(3), 223-236.

Gerdes, H., \& Mallinckrodt, B. (1994). Emotional, social, and academic adjustment of college students: a longitudinal study of retention. Journal of Counseling \& Development, 72(3), 281-288.

Hackett, G., Betz, N. E., Casas, J. M., \& Rocha-Singh, I. A. (1992). Gender, ethnicity, and social cognitive factors predicting the academic achievement of students in engineering. Journal of Counseling Psychology, 39(4), 527-538. 
Halamandaris, K. F., \& Power, K. G. (1999). Individual differences, social support and coping with the examination stress: A study of the psychosocial and academic adjustment of first year home students. Personality and Individual Differences, 26(4), 665-685.

Hurtado, S., Carter, D. F., \& Spuler, A. (1996). Latino student transition to college: assessing difficulties and factors in successful college adjustment. Research in Higher Education, $37(2), 135-157$.

Lidy, K. M., \& Kahn, J. H. (2006). Personality as predictor of first-semester adjustment to college: The mediational role of perceived social support. Journal of College Counselling, 9(2), 123-134.

Martin Jr.,W. E., Swartz, J. L., \& Madson, M. (1999). Psychosocial factors that predict the college adjustment of first-year undergraduate students: implications for college counselors. Journal of College Counseling, 2(2), 121-133.

Mattanah, J., Brooks, L. J., Brand, B. L., Quimby, J. L., \& Ayers, J. (2012). A social support intervention and academic achievement in college: Does perceived loneliness mediate the relationship? Journal of College Counseling, 15(1), 22-35.

Md Aris Safree Md Yasin, \& Mariam Adawiah Dzulkifli (2011). The relationship between social support and academic achievement. International Journal of Humanities and Social Science, 1(5), 277-281.

Napoli, A. R., \& Wortman, P. M. (1998). Psychology factors related to retention and early departure of two-year community college students. Research in Higher Education, 49(4), 419-455.

Norzaini Azman, Manisah Mohd Ali, Abd Halim Tamuri, \& Zalizan Mohd Jelas. (2005). Effective Higher Educational Practices - A Survey of Student Engagement. Malaysian Journal of Learning and Instruction, 2, 1-16.

Parker, J. D. A., Summerfeldt, L. J., Hogan, M. J., \& Majeski, S. A. (2004). Emotional intelligence and academic success: examining the transition from high school to university. Personality and Individual Differences, 36(1), 163-173.

Perry, R. P., Hladkyj, S., Pekrun, R. H., \& Pelletier, S. T. (2001). Academic control in the achievement of college students: A longitudinal field study. Journal of Educational Psychology, 93(4), 776-789. 
Popejoy, M. W. (1994, Feb.). The underprepared student: A student centered process coordination model, responsibilities, recommendations, and results. Orlando. FL. Paper presented in the National Conference on Successful College Teaching.

Salami, S.O. (2011). Psychosocial predictors of adjustment among first year college of education students. US-China Education Review, 8(2), 239-248.

Schneider, M. E., \& Ward, D. J. (2003). The role of ethnic identification and perceived social support in Latinos' adjustment to college. Hispanic Journal of Behavioral Sciences, 25(4), 539-554.

Sennett, J., Finchilescu, G., Gibson, K., \& Strauss, R. (2003). Adjustment of black students at a historically white south African university. Educational Psychology, 23(1), 107-116.

Sharifah Azizah Syed Sahil, \& Rosna Awang Hashim (2011). The roles of social support in promoting adolescent's classroom cognitive engagement through academic self-efficacy. Malaysian Journal of Learning and Instruction, 8, 49-69.

Smith, T., \& Renk, K. (2007). Predictors of academic-related stress in college students: An examination of coping, social support, parenting, and anxiety. NASPA Journal, 44(3), 405-431.

Spitzer, T. M. (2000). Predictors of college success: A comparison of tradisional and nontradisional age students. NASPA Journal, 38(1), 82-98.

Tao, S., Dong, Q., Pratt, M. W., Hunsberger, B., \& Pancer, S. M. (2000). Social support: Relations to coping and adjustment during the transition to university in the Peoples Republic of China. Journal of Adolescent Research, 15(1), 123-144.

Tinto, V. (1993). Leaving college: Rethinking the causes and cures of student attrition (2nd ed.). Chicago: University of Chicago Press.

Yusliza Mohd. Yusoff. (2011). Self-efficacy, perceived social support, and psychological adjustment in international undergraduate students in a public higher education institution in Malaysia. Journal of Studies in International Education [Online journal]. Retrieved from http://jsi.sagepub.com

Zimet, F. D., Dahlem, N. W., Zimet, S. G., \& Farley, G. K. (1988). The multidimensional scale of perceived social support. Journal of Personality Assessment, 52(1), 30-41. 